\title{
Limited protection of macro-aggregate-occluded organic carbon in Siberian steppe soils
}

\author{
Norbert Bischoff $^{1}$, Robert Mikutta ${ }^{2}$, Olga Shibistova ${ }^{1,3}$, Alexander Puzanov ${ }^{4}$, Marina Silanteva ${ }^{5}$, \\ Anna Grebennikova ${ }^{5}$, Roland Fuß ${ }^{6}$, and Georg Guggenberger ${ }^{1,3}$ \\ ${ }^{1}$ Institute of Soil Science, Leibniz Universität Hanover, 30419 Hanover, Germany \\ ${ }^{2}$ Soil Science and Soil Protection, Martin-Luther University Halle-Wittenberg, 06120 Halle, Germany \\ ${ }^{3}$ VN Sukachev Institute of Forest, Siberian Branch of the Russian Academy of Sciences, Krasnoyarsk, \\ 660036, Russian Federation \\ ${ }^{4}$ Institute for Water and Environmental Problems, Siberian Branch of the Russian Academy of Sciences, Barnaul, \\ 656038, Russian Federation \\ ${ }^{5}$ Faculty of Biology, Altai State University, Barnaul, 656049, Russian Federation \\ ${ }^{6}$ Institute of Climate-Smart Agriculture, Johann Heinrich von Thünen Institute, 38116 Braunschweig, Germany \\ Correspondence to: Norbert Bischoff (bischoff@ifbk.uni-hannover.de)
}

Received: 28 November 2016 - Discussion started: 16 January 2017

Revised: 6 April 2017 - Accepted: 10 April 2017 - Published: 24 May 2017

\begin{abstract}
Macro-aggregates especially in agricultural steppe soils are supposed to play a vital role for soil organic carbon (OC) stabilization at a decadal timescale. While most research on soil OC stabilization in steppes focused on North American prairie soils of the Great Plains with information mainly provided by short-term incubation experiments, little is known about the agricultural steppes in southwestern Siberia, though they belong to the greatest conversion areas in the world and occupy an area larger than that in the Great Plains. To quantify the proportion of macro-aggregateprotected OC under different land use as function of land use intensity and time since land use change (LUC) from pasture to arable land in Siberian steppe soils, we determined OC mineralization rates of intact $(250-2000 \mu \mathrm{m})$ and crushed $(<250 \mu \mathrm{m})$ macro-aggregates in long-term incubations over 401 days $\left(20^{\circ} \mathrm{C} ; 60 \%\right.$ water holding capacity) along two agricultural chronosequences in the Siberian Kulunda steppe. Additionally, we incubated bulk soil $(<2000 \mu \mathrm{m})$ to determine the effect of LUC and subsequent agricultural use on a fast and a slow soil OC pool (labile vs. more stable OC), as derived from fitting exponential-decay models to incubation data. We hypothesized that (i) macro-aggregate crushing leads to increased OC mineralization due to an increasing microbial accessibility of a previously occluded labile macroaggregate OC fraction, and (ii) bulk soil OC mineralization
\end{abstract}

rates and the size of the fast $\mathrm{OC}$ pool are higher in pasture than in arable soils with decreasing bulk soil OC mineralization rates and size of the fast $\mathrm{OC}$ pool as land use intensity and time since LUC increase. Against our hypothesis, OC mineralization rates of crushed macro-aggregates were similar to those of intact macro-aggregates under all land use regimes. Macro-aggregate-protected OC was almost absent and accounted for $<1 \%$ of the total macro-aggregate OC content and to a maximum of $8 \pm 4 \%$ of mineralized OC. In accordance to our second hypothesis, highest bulk soil OC mineralization rates and sizes of the fast OC pool were determined under pasture, but mineralization rates and pool sizes were unaffected by land use intensity and time since LUC. However, at one chronosequence mean residence times of the fast and slow OC pool tended to decrease with increasing time since establishment of arable use. We conclude that the tillage-induced breakdown of macro-aggregates has not reduced the OC contents in the soils under study. The decline of OC after LUC is probably attributed to the faster soil $\mathrm{OC}$ turnover under arable land as compared to pasture at a reduced plant residue input. 


\section{Introduction}

Steppe soils comprise about $7 \%$ of the terrestrial soil organic carbon (OC) storage down to $1 \mathrm{~m}$ (see Supplement for calculation) and cover about 885 million hectares worldwide (FAO, 2001). As they are rich in organic matter (OM) and well-suited for agriculture they encompass about $14 \%$ of agricultural land globally (FAO, 2013). Intensive management of steppe soils reduced their OC stocks significantly, with estimated OC losses between 24 and $40 \%$ associated with conversion of grassland to cropland (Beniston et al., 2014; Mikhailova et al., 2000; Rodionov et al., 1998; VandenBygaart et al., 2003). As the stabilization of OC in agricultural soils is crucial for maintaining soil fertility and to reduce the emission of $\mathrm{CO}_{2}$ to the atmosphere (Lal, 2004), further insights into the processes that govern OC stabilization in agricultural steppe soils are needed. Next to temperature and moisture, chemical stabilization by formation of mineral-organic associations and physical disconnection of $\mathrm{OM}$ from microorganisms by occlusion of $\mathrm{OM}$ in aggregates were identified as main factors stabilizing soil OC (Lehmann and Kleber, 2015). For steppe ecosystems the role of aggregation might be more decisive for OC stabilization than the one of mineral-organic associations, as the latter requires sufficient water for the formation of pedogenic minerals and the interaction of $\mathrm{OM}$ with mineral surfaces (Kleber et al., 2015). The potential relevance of aggregate-occluded OC is also suggested by the markedly crumbled soil structure usually found in steppe soils.

The mean residence time of aggregate-occluded OC ranges from decades to several hundreds of years (Six et al., 2002). Tisdall and Oades (1982) proposed a concept in which aggregates are structured hierarchically with respect to their size and binding agents. According to this aggregate hierarchy concept, primary particles or silt-sized aggregates $(<20 \mu \mathrm{m})$ are bound together to micro-aggregates $(<250 \mu \mathrm{m})$ by persistent binding agents, e.g., humified OM, polyvalent metal cations or oxides. The micro-aggregates, in turn, are linked together to form larger macro-aggregates ( $>250 \mu \mathrm{m}$ ) by temporary (e.g., fungal hyphae, roots) or transient binding agents (e.g., microbial and plant-derived polysaccharides). Due to the hierarchical order of aggregate structure and the different persistence of the involved binding agents, macro-aggregates are less stable and more vulnerable to soil management than micro-aggregates (Tisdall and Oades, 1982). Accordingly, Six et al. (2000b) showed that macro-aggregates disintegrated more readily upon disturbance than micro-aggregates, particularly in soils with increasing cultivation intensity. By that, macro-aggregateoccluded OC becomes available to microbial decomposition, hence, this fraction is supposed to play an important role for the decline of soil OC in intensively managed steppe soils (Cambardella and Elliott, 1993, 1994; Elliott, 1986). Furthermore, previous work indicated decreasing amounts of labile $\mathrm{OM}$ and $\mathrm{OC}$ mineralization rates with increasing dura- tion and intensity of agricultural management (Cambardella and Elliot, 1992; Grandy and Robertson, 2007; Hurisso et al., 2014).

One way to quantify the proportion of macro-aggregateprotected soil OC is to compare mineralization rates from intact and crushed macro-aggregates. Previous studies found an increase of soil OC mineralization after macro-aggregate crushing (Beare et al., 1994; Bossuyt et al., 2002; Elliott, 1986; Gupta and Germida, 1988; Pulleman and Marinissen, 2004), though not all studies revealed consistent results (Garcia-Oliva et al., 2004; Goebel et al., 2009; Plante et al., 2009; Tian et al., 2015). Moreover, OC mineralization after macro-aggregate crushing differed also with respect to land use. Pulleman and Marinissen (2004) found larger OC mineralization after crushing of macro-aggregates in croplands than in grasslands and ascribed this to the physicogenic nature of macro-aggregates in arable soils, which have smaller pore sizes than biogenic macro-aggregates in grasslands, and therefore larger protection capacity. Also Elliott (1986) observed the increase of OC mineralization with macroaggregate crushing to be more pronounced in arable than in grassland soils, while Gupta and Germida (1988) observed the opposite effect. A shortcoming of previous studies is the short incubation period of only few weeks under largely nonequilibrium conditions, which results in an unreliable assessment of the size of the macro-aggregate-protected OC fraction and its turnover time. This fact, therefore, asks for longterm incubation experiments to address the vulnerability of macro-aggregate-protected OC.

The majority of research on OC protection in aggregates of steppe soils focused on prairie soils of the Great Plains, while little is known for Siberian steppe soils. This is surprising as the steppe ecosystems in Siberia belong to the greatest agricultural production areas in the world with an area greater than that of the Great Plains and cover some of the most intensively managed soils globally (Frühauf, 2011). In the West Siberian Plain $420000 \mathrm{~km}^{2}$ natural steppe was converted into cropland between 1954 and 1963 in the frame of the "Virgin Lands Campaign" (Russian: Zelina). Conversion from grassland to cropland reduced soil OC stocks by about $31 \%$ in $0-25 \mathrm{~cm}$, of which most occurred within the first years after land conversion and was associated with a decline in aggregate stability (Bischoff et al., 2016). This indicated an interrelation between aggregate stability and OC storage also in these soils. Moreover, Bischoff et al. (2016) found about $10 \%$ of OC in the studied soils was existent in particulate OM of which some is probably occluded within aggregates. In the present study we aimed to quantify the proportion of macro-aggregate-protected OC under different land use as function of land use intensity and time since land use change (LUC) from pasture to arable land in Siberian steppe soils. This was done by comparing OC mineralization rates of intact $(250-2000 \mu \mathrm{m})$ and crushed $(<250 \mu \mathrm{m})$ macro-aggregates in long-term incubations over 401 days along two agricultural chronosequences of the southwest- 
ern Siberian Kulunda steppe. In addition, bulk soil samples $(<2000 \mu \mathrm{m})$ were incubated to determine the effect of LUC from pasture to arable land on a fast and a slow soil OC pool (labile vs. more stable OC), as derived from fitting exponential-decay models to incubation data. We hypothesized that (i) crushing of macro-aggregates leads to increased OC mineralization due to an increasing microbial accessibility of a previously occluded labile macro-aggregate OC fraction, and (ii) bulk soil OC mineralization rates and the size of the fast soil OC pool are higher in pasture than in arable soils with decreasing bulk soil OC mineralization rates and size of the fast OC pool as land use intensity and time since LUC increase. In this study, we refer to fractions as physically separated soil OC components (macro-aggregate-occluded soil OC), while pools refer to mathematically derived OC constituents from fitting exponential-decay models to incubation data (fast and slow soil OC pool).

\section{Material and methods}

\subsection{Study sites and soil sampling}

The Kulunda steppe is part of the Russian Federation (Altayskiy Kray) and located within the steppes of southwestern Siberia. We selected two sites in two different steppe types, which were characterized by different climate and distinct soil texture (Fig. 1). Within a site the texture of the soils was comparable. The first site is located in the forest steppe (FS) near Pankrushikha $\left(53^{\circ} 44^{\prime} 19.53^{\prime \prime} \mathrm{N}, 80^{\circ} 41^{\prime} 2.88^{\prime \prime} \mathrm{E}\right)$ with a mean annual precipitation (MAP) of $368 \mathrm{~mm}$ and a mean annual temperature (MAT) of $1.1^{\circ} \mathrm{C}$ (Table 1). The second site is situated near Sidorovka $\left(52^{\circ} 30^{\prime} 1.43^{\prime \prime} \mathrm{N}, 80^{\circ} 44^{\prime} 41.68^{\prime \prime} \mathrm{E}\right)$ and part of the typical steppe (TS) with a MAP of $339 \mathrm{~mm}$ and a MAT of $2.0^{\circ} \mathrm{C}$, which is more arid than FS (climate data from "WorldClim" data base; Hijmans et al., 2005). We identified the two sites by interviewing farmers and land owners about land use history and management. The plots within a site were checked for comparable pedological conditions by inspecting the soils with a hand auger. Soil sampling took place in 2013. At each site we identified a land use chronosequence with four plots. At FS, we also included two plots with varying land use intensity (extensive pasture vs. arable land with forage crops). The FS site comprised an extensive pasture (vegetation: Festuca valesiaca Fillipendula vulgaris - Bromopsis inermis), an arable land with forage crops and arable land after 5 and 30 years of cultivation (arable 5 years, arable 30 years). Crop rotations on the arable 5 years and arable 30 years included summer wheat, summer barley, and peas. The soils were classified as Protocalcic Chernozems (Siltic) according to IUSS Working Group WRB (2014). The TS site consisted of four plots that have been all cultivated since the 1950s (Zelina) but left as fallow since 1983 because of low agricultural productivity. After 1983 all plots were used extensively as pas-

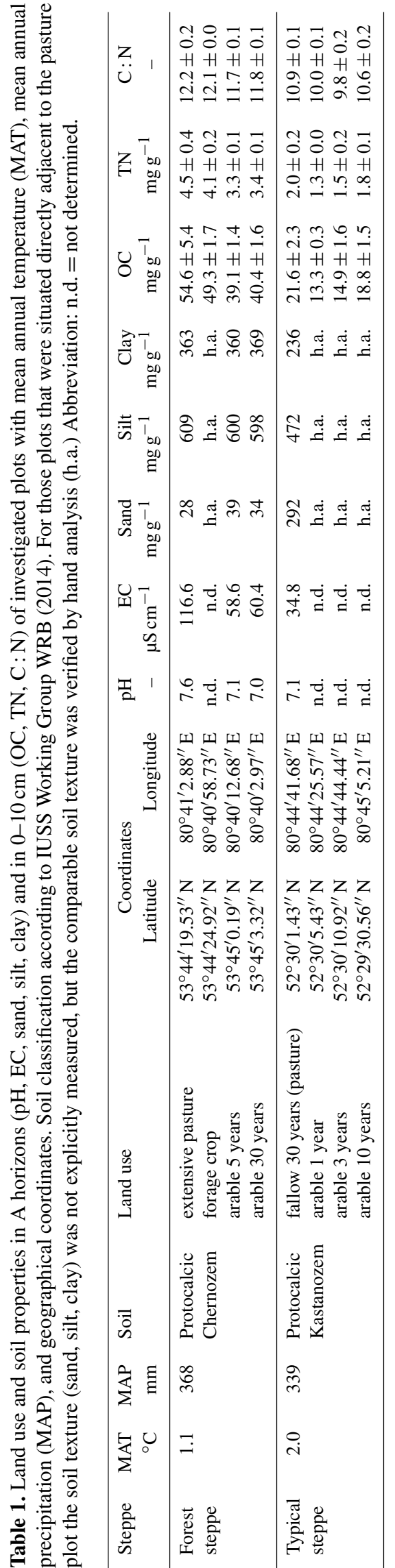

www.biogeosciences.net/14/2627/2017/

Biogeosciences, 14, 2627-2640, 2017 


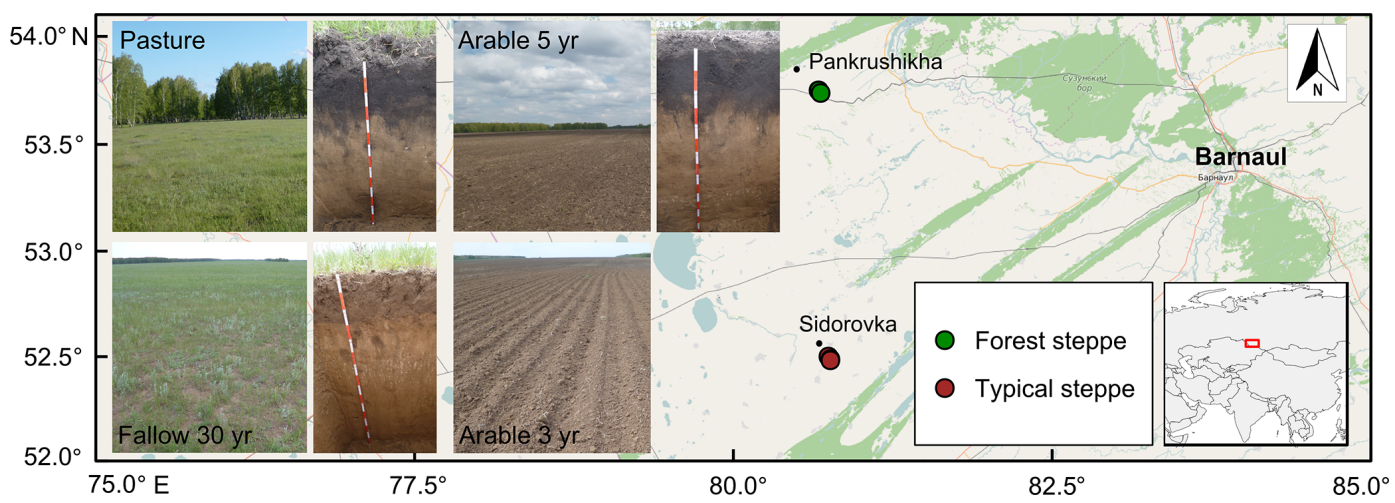

Figure 1. Map of the study area and pictures from the two sites near Pankrushikha and Sidorovka. Map modified from @OOpenStreetMap contributors, for copyright see www.openstreetmap.org/copyright.

ture but three of the four plots were recultivated at different points in time, allowing for a chronosequence with a 30year old fallow (meanwhile used as pasture) and plots with 1-, 3-, and 10-year arable land use (arable 1 year, arable 3 years, arable 10 years). The 30 -year old fallow (pasture) is characterized by Agropyron pectinatum, Bromopsis inermis, and Artemisia glauca. The absence of some typical steppe species, such as Stipa sp. or Festuca sp., and the sparse vegetation cover (Fig. 1) pointed to the fact that the vegetation of this plot was degraded from grazing. The site was located on a small hillslope with $<2^{\circ}$ inclination, where the fallow plot of 30 years was located at the highest point and the arable plot of 10 years at the base level. Though the inclination was very small, we measured larger soil OC contents in the arable 10-year plot than in the upslope arable 1-year and arable 3year plots, which we attributed to erosion. Nevertheless, we decided to include this site in our study, as chronosequences are very sparse in the study area and the possible effect of macro-aggregate crushing on soil OC mineralization, if existent, will be also evident on slightly eroded plots. Soils at the TS site were classified as Protocalcic Kastanozem (Loamic). At both sites characteristic key profiles were identified and established from 0 to $150 \mathrm{~cm}$ on the pasture plots for soil description and sampled in horizons. As the arable 5-year and arable 30-year plots at the FS site were $>500 \mathrm{~m}$ distant from the other two plots, we additionally established a key profile on each of these two plots. All other plots were located directly adjacent to the pasture plot of the respective site, and checking the plots with a hand auger showed that key profiles from pasture plots were also representative for these plots. Hence, no additional key profiles were established on these plots. Key profile samples were analyzed for $\mathrm{pH}$, soil texture, and electrical conductivity (EC). For those plots where no key profile was excavated a comparable soil texture between plots within a site was verified by hand analysis. Further, on all plots three additional soil samples (field replicates) were randomly collected in $0-10 \mathrm{~cm}$ depth for determination of soil OC and total nitrogen (TN) content and for use in the soil incubation experiment.

\subsection{Sample preparation and basic soil analyses}

Soil samples were air-dried and sieved to $<2 \mathrm{~mm}$. Big clods were gently broken apart to pass the $2 \mathrm{~mm}$ sieve and all visible plant residues were removed. A subsample was dried at $105^{\circ} \mathrm{C}$ for $24 \mathrm{~h}$ to determine the residual soil water content, which was subtracted from air-dry samples for calculation of elemental contents. Another subsample was homogenized with a ball mill (Retsch MM200, Haan, Germany) and measured for OC and TN via dry combustion with an Elementar vario MICRO cube C/N Analyzer (Elementar Analysensysteme GmbH, Hanau, Germany). Traces of inorganic carbon $\left(\mathrm{CaCO}_{3}\right.$ content $\left.<0.1 \%\right)$ were previously removed by $\mathrm{HCl}$ fumigation (Walthert et al., 2010). Organic C and TN measurements were done prior the incubation experiment. Soil $\mathrm{pH}$ was measured at a $1: 2.5(w: v)$ soil-to-water ${ }_{\text {deion }}$ ratio after leaving the suspensions for 1 day to reach equilibrium, and soil EC was measured at a soil-to-water deion $_{\text {ratio of } 1: 5}$ $(w: v)$. The texture of the soils was determined according to the standard sieve-pipette method (DIN ISO 11277, 2002).

\subsection{Aggregate crushing and incubation of soil samples}

Each of the samples from 0 to $10 \mathrm{~cm}$ was divided into three fractions: (i) bulk soil $(<2000 \mu \mathrm{m})$, (ii) intact macro-aggregates $(250-2000 \mu \mathrm{m})$, and (iii) crushed macroaggregates $(<250 \mu \mathrm{m})$. Intact macro-aggregates were isolated by gently sieving the air-dry bulk soil through a $250 \mu \mathrm{m}$ sieve and using the fraction remaining on the sieve. A subsample from the intact macro-aggregates was crushed in a mortar and sieved again through the $250 \mu \mathrm{m}$ sieve to obtain the fraction of crushed macro-aggregates $(<250 \mu \mathrm{m})$. We decided to use dry-sieved aggregates for soil incubation as wet sieving releases soluble $\mathrm{OM}$, which is bioavailable and thus a critical fraction for soil OC mineralization (Sainju, 2006). Further, microbial activity is less affected by dry sieving than 
by wet sieving (Sainju, 2006). All samples of the three fractions were divided into three analytical replicates, giving a total of 216 samples for soil incubations $(8$ plots $\times 3$ field replicates $\times 3$ fractions $\times 3$ analytical replicates).

To determine whether the crushed macro-aggregates consisted of intact micro-aggregates or primary particles, a subsample of crushed macro-aggregates was sieved through a $63 \mu \mathrm{m}$ sieve and obtained fractions were quantified by mass balance calculations and subsequently imaged by a JEOL JSM-6390A scanning electron microscope (JEOL Ltd., Tokyo, Japan). Our analysis revealed that $62.1 \pm 3.2 \%$ of crushed macro-aggregates still existed as large microaggregates $(>63 \mu \mathrm{m})$ while $37.9 \pm 3.2 \%$ were found in the fraction $<63 \mu \mathrm{m}$, which mainly consisted of small microaggregates and only few primary particles (Fig. S1 in the Supplement).

Soil laboratory incubations were carried out under aerobic conditions in the dark, at constant temperature of $20^{\circ} \mathrm{C}$ and $60 \%$ of maximum water holding capacity (WHC), which was determined according to Schlichting et al. (1995). An amount of $7.5 \mathrm{~g}$ soil sample was mixed with $12.5 \mathrm{~g}$ combusted $\left(1000^{\circ} \mathrm{C}\right.$ for $\left.24 \mathrm{~h}\right)$ quartz powder (Roth, Karlsruhe, Germany; $>99 \%$ pulverized, $<125 \mu \mathrm{m})$ and filled into $120 \mathrm{~mL}$ glass jars. Quartz powder was used to increase the sample volume and prevent the formation of aggregates in the crushed samples. Three jars were solely filled with quartz and used as control. Soil moisture was regulated during the experiment by periodically weighing the glass jars and adding ultrapure water. All samples were pre-incubated for 14 days and respiration measurements were subsequently taken at days $1,3,8,14,21,28,57,98,127,196,268$, and 401 by sampling the headspace of each jar using a syringe through a septum, which was installed in the jar lids prior to sampling. Gas samples were analyzed for $\mathrm{CO}_{2}$ concentrations with a Shimadzu GC-2014 modified according to Loftfield et al. (1997).

\subsection{Determination of microbial biomass}

After the laboratory incubations all incubated samples were analyzed for microbial biomass $\mathrm{C}$ using the chloroform fumigation-extraction method (Vance et al., 1987). Briefly, $6 \mathrm{~g}$ soil were kept at $60 \% \mathrm{WHC}$ and weighed in duplicate into glass jars. One sample was fumigated with ethanol-free $\mathrm{CHCl}_{3}$ during $24 \mathrm{~h}$ while the other sample was left unfumigated. Both, fumigated and unfumigated samples, were extracted with $0.5 \mathrm{M} \mathrm{K}_{2} \mathrm{SO}_{4}$ at a soil-to-solution ratio of $1: 10$ $(w: v)$, shaken for $30 \mathrm{~min}$, and subsequently centrifuged at $2700 \mathrm{~g}$. The extracts were filtered (Whatman filter paper, ashless, grade 42) and measured for non-purgeable organic carbon (NPOC) by a LiquiTOC (Elementar Analysensysteme $\mathrm{GmbH}$, Hanau, Germany). Microbial biomass $\mathrm{C}$ was calculated as the difference between fumigated and unfumigated

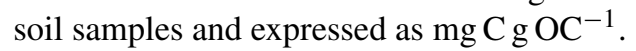

\subsection{Calculations and statistical analyses}

All data analyses were carried out in R 3.1.2 (R Core Team, 2015). To calculate cumulative respiration rates, data of $\mathrm{CO}_{2}$ measurements per day was interpolated by spline interpolation for each sample (i.e., analytical replicate) separately. Cumulative respiration rates were analyzed by fitting three different exponential-decay models to the data and choosing the model with the best fit by AIC (Akaike Information Criterion) selection. The first model was a first-order exponentialdecay model with one pool (one-pool model; Eq. 1):

$C_{\text {remain }}=C_{1} \times e^{\left(-k_{1} \times t\right)}$.

The second model consisted of two pools (two-pool model; Eq. 2):

$C_{\text {remain }}=C_{1} \times e^{\left(-k_{1} \times t\right)}+C_{2} \times e^{\left(-k_{2} \times t\right)}$.

The third model was an asymptotic first-order exponentialdecay model with two pools (asymptotic two-pool model; Eq. 3):

$C_{\text {remain }}=C_{1} \times e^{\left(-k_{1} \times t\right)}+C_{2}$,

where $C_{\text {remain }}$ is the amount of OC remaining in the sample, $C_{1}$ and $C_{2}$ are the sizes of the fast and the slow pool, respectively, $k_{1}$ and $k_{2}$ the rate constant of the fast and the slow pool, respectively, and $t$ the time. For the majority of samples the two-pool model (Eq. 2) showed the best fit. Only for the pasture plot at FS the incubation time was too short to calculate the rate constant $k$ for the slow pool; thus, the asymptotic two-pool model (Eq. 3) fitted the data best. The mean residence time (MRT) was calculated as $1 / k$. The modeled parameters were used in linear mixed effects models (package lme4; Bates et al., 2012) to test for significant differences between soil fractions within plots, accounting for the nested structure of sampling by using the field replicates within each plot as random effects. Moreover, random slopes were included by allowing field replicates within each plot to have random slopes for the effect of soil fraction. Based on the linear mixed-model fit, we tested whether differences of the dependent variable between soil fractions within plots were significant, including corrections for multiple comparisons (analogous to the Tukey test) with Satterthwaite degrees of freedom, using the $\mathrm{R}$ packages lsmeans (Lenth and Herve, 2015), lmerTest (Kuznetsova et al., 2015), and multcomp (Hothorn et al., 2008). Model assumptions were checked using residuals vs. fitted plots and $Q-Q$ plots for the residual errors and random effect estimates. The proportion of the macro-aggregate-protected OC fraction to the total macroaggregate OC content was calculated by Eq. (4):

$C_{\text {macro, total aggrC }}=C_{\text {min, crushed }}-\frac{1}{n} \sum_{i=1}^{n} C_{\text {min, intact }}$,

where $C_{\text {macro, total aggrC }}$ is the proportion of macro-aggregateprotected OC to the total macro-aggregate OC (\%), 


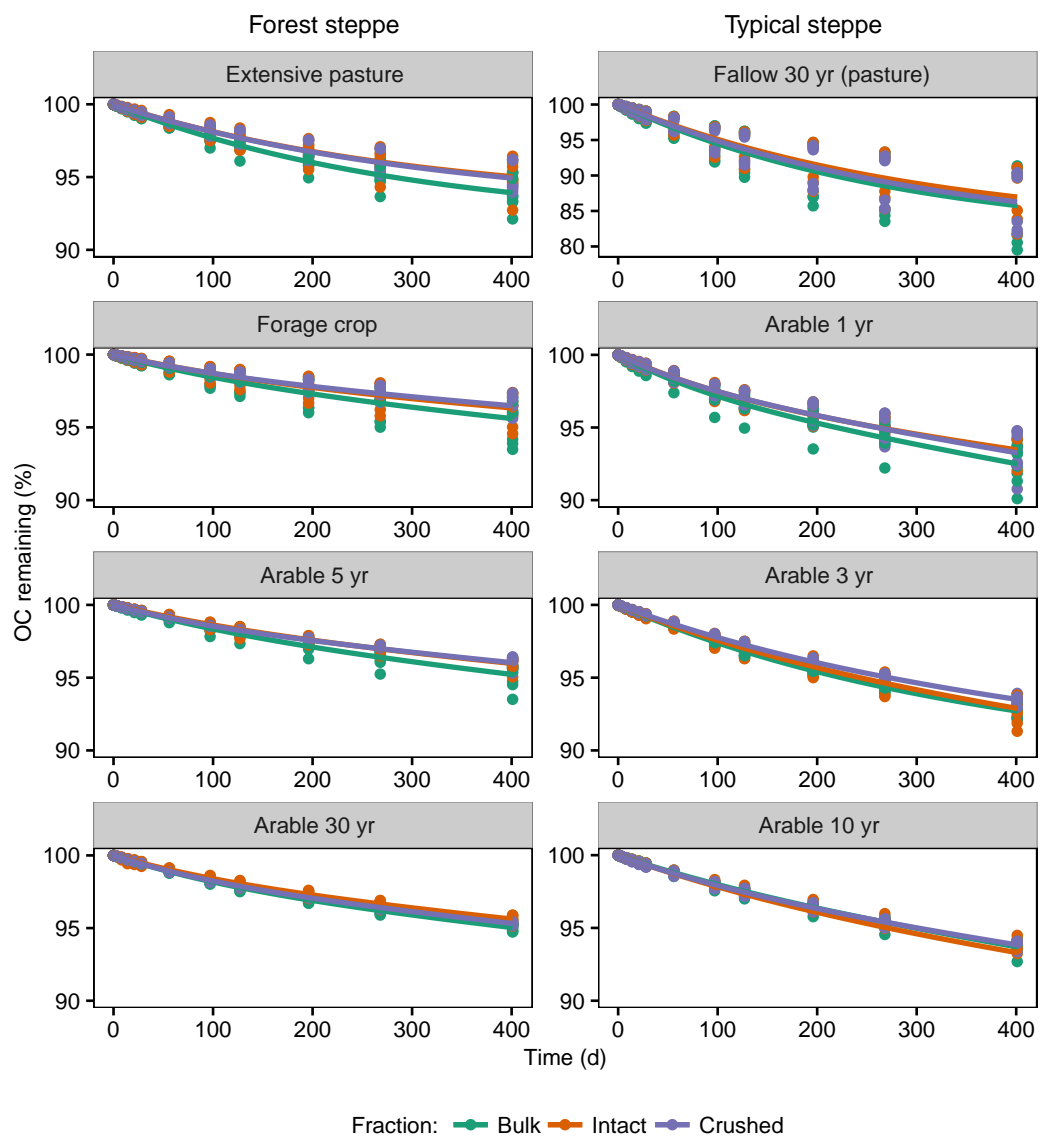

Figure 2. Percentage of soil OC remaining in the samples during 401 days of incubation for eight plots within two steppe types and for the three fractions bulk soil, intact macro-aggregates, and crushed macro-aggregates. For all plots a two-pool model (Eq. 2) was fitted, except for the extensively managed plots (extensive pasture and the fallow 30 years (pasture)), where an asymptotic two-pool model was fitted (Eq. 3). Note the different $y$ scale for the fallow 30 years (pasture).

$C_{\text {min, crushed }}$ is the proportion of OC mineralized in the crushed macro-aggregates $(\%)$, and $C_{\text {min, intact }}$ is the proportion of OC mineralized in the intact macro-aggregates $(\%)$, while $n$ is the number of analytical replicates per field replicate for the treatment of intact macro-aggregates and $i$ is the $i$ th analytical replicate per field replicate. The proportion of the macro-aggregate-protected OC fraction to the total mineralized OC as function of time was calculated by Eq. (5):

$$
\begin{aligned}
& C_{\text {macro, mineralizableC }}(t)= \\
& \frac{C_{\text {min, crushed }}(t)-\frac{1}{n} \sum_{i=1}^{n} C_{\text {min, intact }}(t)}{C_{\text {min, crushed }}(t)} \times 100,
\end{aligned}
$$

where $C_{\text {macro, mineralizableC }}(t)$ is the proportion (\%) of macroaggregate-protected $\mathrm{OC}$ to the total mineralized $\mathrm{OC}$ at time $t$ (days). Graphs were generated using ggplot2 (Wickham, 2009). Box plots show the median, the first, and the third quartile, and the whiskers extend from the box to the highest or lowest value, respectively, which is within $1.5 \times$ inter-quartile range. Individual measurements are plotted as points.

\section{Results}

\subsection{Basic soil characteristics and organic carbon contents along the chronosequences}

The soil pH of A horizons was characteristic for Chernozems and Kastanozems and ranged between 7.0 and 7.6, while EC was low and did not exceed $120 \mu \mathrm{sm}^{-1}$ at both sites (Table 1). In FS, soil OC contents decreased as a result of LUC from pasture to arable land from $55 \pm 5 \mathrm{mg} \mathrm{g}^{-1}$ under extensive pasture to $39 \pm 1$ and $40 \pm 2 \mathrm{mg} \mathrm{g}^{-1}$ under arable 5year and arable 30-year plots, respectively (Table 1). Thus, increasing duration of agricultural land use caused no further decrease of soil OC contents in arable soils. $\mathrm{C}: \mathrm{N}$ ratios were around 12 and slightly higher for non-arable than for arable soils. Soil OC contents in TS were smaller than in FS and did not follow the gradient over time since cultivation, as the site 
Table 2. Mean residence times of the fast and slow OC pool (years) as arithmetic mean \pm standard error (SE), as derived from least-square fitting of incubation data, for two steppe types and as function of land use and soil fraction. Significant differences $(p<0.05)$ between fractions within land use were not detected, which is indicated by same lowercase letters.

\begin{tabular}{|c|c|c|c|c|}
\hline \multirow[t]{2}{*}{ Steppe } & \multirow[t]{2}{*}{ Land use } & \multirow[t]{2}{*}{ Fraction } & \multicolumn{2}{|c|}{ Mean residence time (years) } \\
\hline & & & Fast OC pool & Slow OC pool \\
\hline \multirow[t]{12}{*}{ Forest steppe } & extensive pasture & bulk & $0.73 \pm 0.07 \mathrm{a}$ & $62.8 \pm 18.6 \mathrm{a}$ \\
\hline & & intact & $0.74 \pm 0.09 \mathrm{a}$ & $54.5 \pm 1.6 \mathrm{a}$ \\
\hline & & crushed & $0.69 \pm 0.06 \mathrm{a}$ & $89.5 \pm 19.2 \mathrm{a}$ \\
\hline & forage crop & bulk & $0.46 \pm 0.07 \mathrm{a}$ & $53.5 \pm 7.6 \mathrm{a}$ \\
\hline & & intact & $0.68 \pm 0.11 \mathrm{a}$ & $65.2 \pm 13.6 \mathrm{a}$ \\
\hline & & crushed & $0.42 \pm 0.06 \mathrm{a}$ & $48.3 \pm 3.3 \mathrm{a}$ \\
\hline & arable 5 years & bulk & $0.51 \pm 0.07 \mathrm{a}$ & $45.2 \pm 8.0 \mathrm{a}$ \\
\hline & & intact & $0.51 \pm 0.06 \mathrm{a}$ & $48.1 \pm 6.4 \mathrm{a}$ \\
\hline & & crushed & $0.33 \pm 0.02 \mathrm{a}$ & $42.4 \pm 3.1 \mathrm{a}$ \\
\hline & arable 30 years & bulk & $0.38 \pm 0.02 \mathrm{a}$ & $36.5 \pm 1.6 \mathrm{a}$ \\
\hline & & intact & $0.41 \pm 0.03 \mathrm{a}$ & $41.5 \pm 1.9 \mathrm{a}$ \\
\hline & & crushed & $0.33 \pm 0.01 \mathrm{a}$ & $36.9 \pm 1.7 \mathrm{a}$ \\
\hline \multirow[t]{12}{*}{ Typical steppe } & fallow 30 years (pasture) & bulk & $0.79 \pm 0.11 \mathrm{a}$ & $21.7 \pm 7.1 \mathrm{a}$ \\
\hline & & intact & $0.79 \pm 0.10 \mathrm{a}$ & $25.8 \pm 2.4 \mathrm{a}$ \\
\hline & & crushed & $0.80 \pm 0.10 \mathrm{a}$ & $25.9 \pm 9.0 \mathrm{a}$ \\
\hline & arable 1 year & bulk & $0.33 \pm 0.06 \mathrm{a}$ & $26.2 \pm 4.9 \mathrm{a}$ \\
\hline & & intact & $0.43 \pm 0.05 \mathrm{a}$ & $30.9 \pm 3.2 \mathrm{a}$ \\
\hline & & crushed & $0.32 \pm 0.05 \mathrm{a}$ & $30.3 \pm 6.6 \mathrm{a}$ \\
\hline & arable 3 years & bulk & $0.68 \pm 0.11 \mathrm{a}$ & $29.5 \pm 4.0 \mathrm{a}$ \\
\hline & & intact & $0.64 \pm 0.14 \mathrm{a}$ & $20.6 \pm 1.3 \mathrm{a}$ \\
\hline & & crushed & $0.88 \pm 0.16 \mathrm{a}$ & $22.7 \pm 2.7 \mathrm{a}$ \\
\hline & arable 10 years & bulk & $0.55 \pm 0.08 \mathrm{a}$ & $24.4 \pm 1.4 \mathrm{a}$ \\
\hline & & intact & $0.86 \pm 0.18 \mathrm{a}$ & $33.2 \pm 7.2 \mathrm{a}$ \\
\hline & & crushed & $0.58 \pm 0.10 \mathrm{a}$ & $25.9 \pm 1.6 \mathrm{a}$ \\
\hline
\end{tabular}

was affected by erosion (Sect. 2.1). In TS, soil $\mathrm{C}: \mathrm{N}$ ratios were around 10-11 and slightly larger for the fallow 30-year plot (pasture) than for the arable soils.

\subsection{Effect of macro-aggregate crushing on the mineralization of soil organic carbon}

Mass balance calculations revealed that in both steppe types about $70 \%$ of $\mathrm{OC}$ was associated with macro-aggregates, indicating the importance of macro-aggregates for the $\mathrm{OC}$ dynamics in these soils. Organic $\mathrm{C}$ and $\mathrm{TN}$ contents did not vary considerably between intact and crushed macro-aggregates (Table S1 in the Supplement). As is typically for soil incubations, respiration rates were higher at the beginning and decreased with increasing incubation time (Fig. S2). The amount of OC remaining in the sample during incubation was described by either two-pool (Eq. 2) or asymptotic twopool models (Eq. 3) (Fig. 2). The variability of the percentage residual $\mathrm{OC}$ within one plot decreased with increasing time since LUC (Fig. 2). This means that soil samples belonging to the plots with the longest cultivation history were more similar to each other than samples from plots in more pristine state. The amount of soil OC mineralized was slightly larger in the bulk soil fraction $(<2000 \mu \mathrm{m})$ than in the intact and crushed macro-aggregates in all plots along the two chronosequences, though significant differences were only observed in soils of FS ( $p<0.05$, Fig. 3 ).

There was no significant difference in soil OC mineralization between intact and crushed macro-aggregates after 401 days of incubation in all plots under study (Fig. 3). The fraction of macro-aggregate-protected $\mathrm{OC}$ was practically non-existent and accounted for $<1 \%$ of the total macroaggregate OC content in all plots (data not shown). Furthermore, macro-aggregate crushing did not increase the size of the fast soil OC pool, which was determined by fitting exponential-decay models to the incubation data (Fig. 4). Also the MRT of the fast and the slow OC pool was unaffected by macro-aggregate crushing (Table 2). However, we could determine a small contribution of the macro-aggregateprotected OC fraction to the total OC mineralization during the beginning of the incubation in seven out of eight plots, where macro-aggregate-protected $\mathrm{OC}$ contributed to about $10 \%$ to the total mineralized $\mathrm{OC} \mathrm{d}^{-1}$ (Fig. 5). Cumulated over the entire incubation period, the contribution of the macro-aggregate-protected $\mathrm{OC}$ fraction to the total $\mathrm{OC}$ mineralization was non-existent or very small and amounted to 

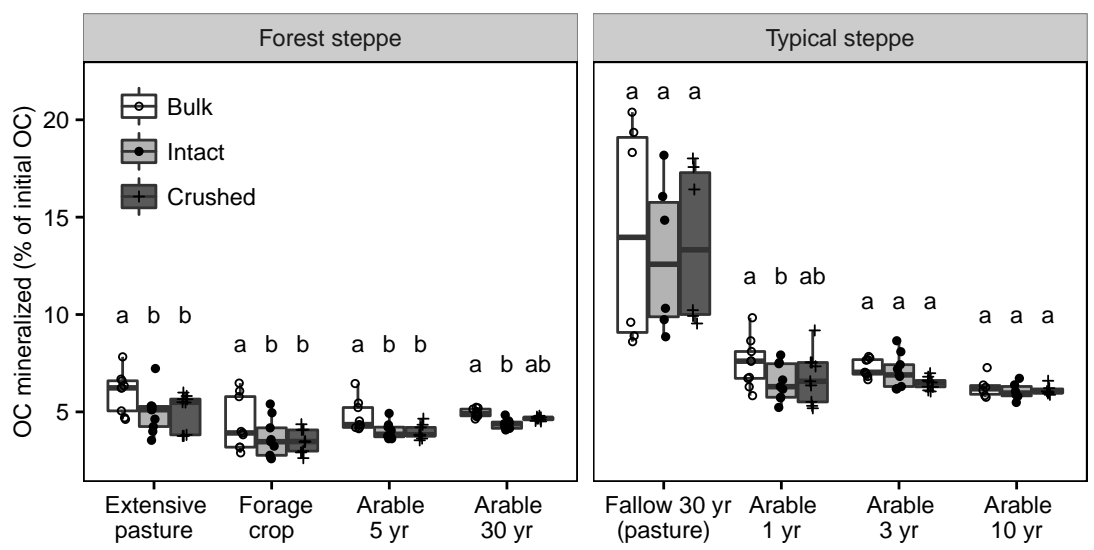

Figure 3. Percentage of soil OC mineralized during 401 days of incubation for eight plots within two steppe types and for the three fractions bulk soil, intact macro-aggregates, and crushed macro-aggregates. Different lowercase letters indicate significant differences $(p<0.05)$ between fractions within plots.
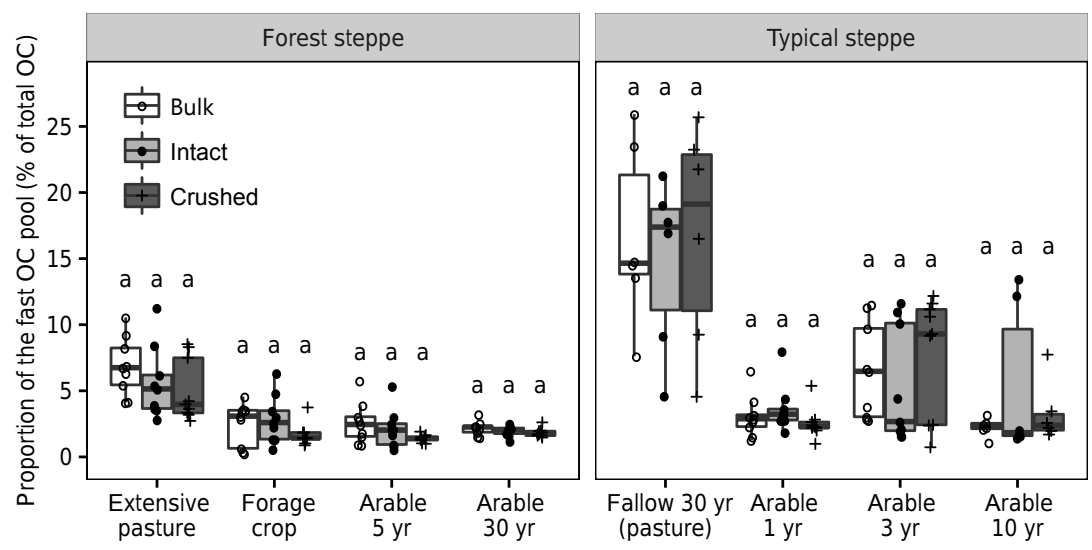

Figure 4. Proportion of the fast OC pool (\% of total OC) for eight plots within two steppe types and for the three fractions bulk soil, intact macro-aggregates, and crushed macro-aggregates as derived from two-pool model fits to incubation data (Eqs. 2 and 3 ). Significant differences $(p<0.05)$ between fractions within plots were not detected, which is indicated by same lowercase letters.

between zero and $8 \pm 4 \%$ in seven out of eight plots with no clear trend with respect to the time since LUC (Table 3). The arable 3-year plot in TS had clearly negative values of macroaggregate-protected $\mathrm{OC}$, which resulted from a lower OC mineralization in crushed than in intact macro-aggregates. For most plots, the negligible fraction of macro-aggregateprotected $\mathrm{OC}$ was depleted between 100 and 400 days, while the arable 30-year plot in FS and the fallow 30-year plot (pasture) in TS showed a constant but small (ca. $5 \%$ ) mineralization rate of macro-aggregate-protected OC during the complete incubation period (Fig. 5).

\subsection{Soil organic carbon mineralization along the chronosequences}

The bulk soil OC mineralization declined after LUC from pasture to arable land in both steppe types, but we only observed a trend of decreasing soil OC mineralization in TS with increasing time since LUC (Fig. 3). Likewise, the pro- portion of the fast soil OC pool decreased as a result of LUC, but it was unaffected by the intensity and time since the establishment of arable land use (Fig. 4). The MRT of the fast OC pool became shorter in the course of LUC in both steppe types, but we only observed a trend towards shorter MRTs in FS with increasing land use intensity and time since LUC (Table 2). With respect to the slow soil OC pool, we only detected shorter MRTs in FS due to conversion of pasture to arable land and with increasing land use intensity and time since conversion to arable land use, whereas no trend was apparent along the chronosequence in TS (Table 2). In general, the amount of soil OC mineralized was slightly larger in TS than in FS, while the differences were most pronounced between the pasture plots (Fig. 3). Remarkable was the pasture in TS, which had clearly the largest OC mineralization and proportion of the fast OC pool but, at the same time, also the highest variability (Figs. 3 and 4). 
Table 3. Proportion of macro-aggregate-protected OC (\% of mineralized OC) as arithmetic mean \pm SE for two steppe types and the respective land use. Since the proportion of macro-aggregate-protected OC has been calculated by subtracting the amount of OC mineralized in intact macro-aggregates from that in crushed macro-aggregates, negative values occur when the OC mineralization was smaller in crushed than in intact macro-aggregates.

\begin{tabular}{llr}
\hline Steppe & Land use & $\begin{array}{r}\text { Macro-aggregate-protected OC } \\
\text { (\% of mineralized OC) }\end{array}$ \\
\hline \multirow{2}{*}{ Forest steppe } & extensive pasture & $1.4 \pm 2.4$ \\
& forage crop & $-0.4 \pm 8.4$ \\
& arable 5 years & $2.6 \pm 4.3$ \\
Typical steppe & arable 30 years & $7.7 \pm 4.2$ \\
& fallow 30 years (pasture) & $4.7 \pm 0.8$ \\
& arable 1 year & $0.7 \pm 1.8$ \\
& arable 3 years & $-8.8 \pm 5.7$ \\
& arable 10 years & $4.3 \pm 3.1$ \\
\hline
\end{tabular}

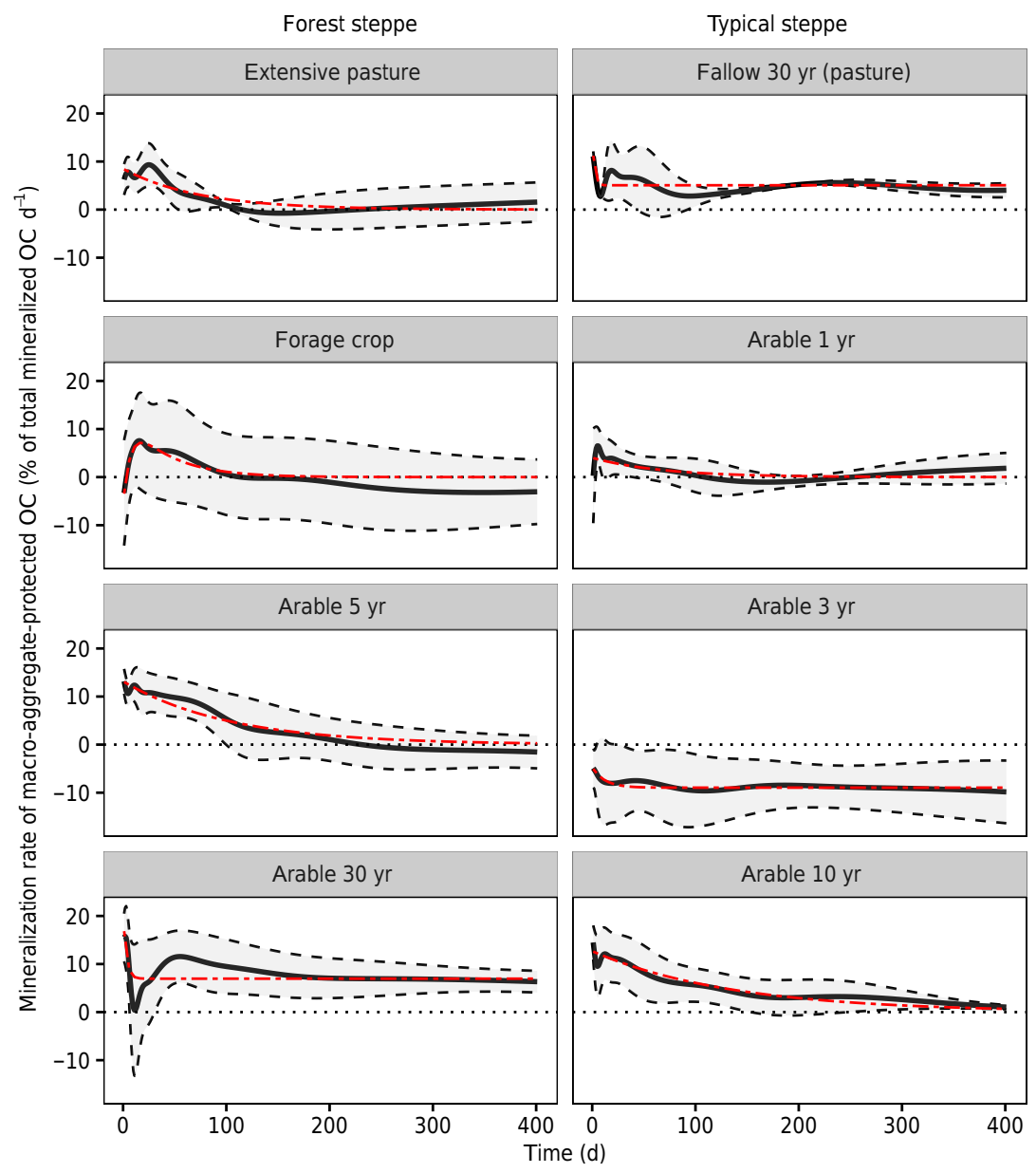

Figure 5. Mineralization rate of macro-aggregate-protected OC ( $\%$ of total mineralized $\mathrm{OC}^{-1}$ ) during 401 days of incubation for eight plots within two steppe types. The black solid line shows the mean mineralization rate per plot and the shaded gray area (confined by the black dashed lines) shows the corresponding standard error. The red dot-dashed line shows the fit of an exponential-decay model (either onepool model, two-pool model, or asymptotic two-pool model according to the best fit). Since the mineralization rates have been calculated by subtracting the OC mineralization rates of intact macro-aggregates from that of crushed macro-aggregates, negative values occur when the OC mineralization was smaller in crushed than in intact macro-aggregates. 

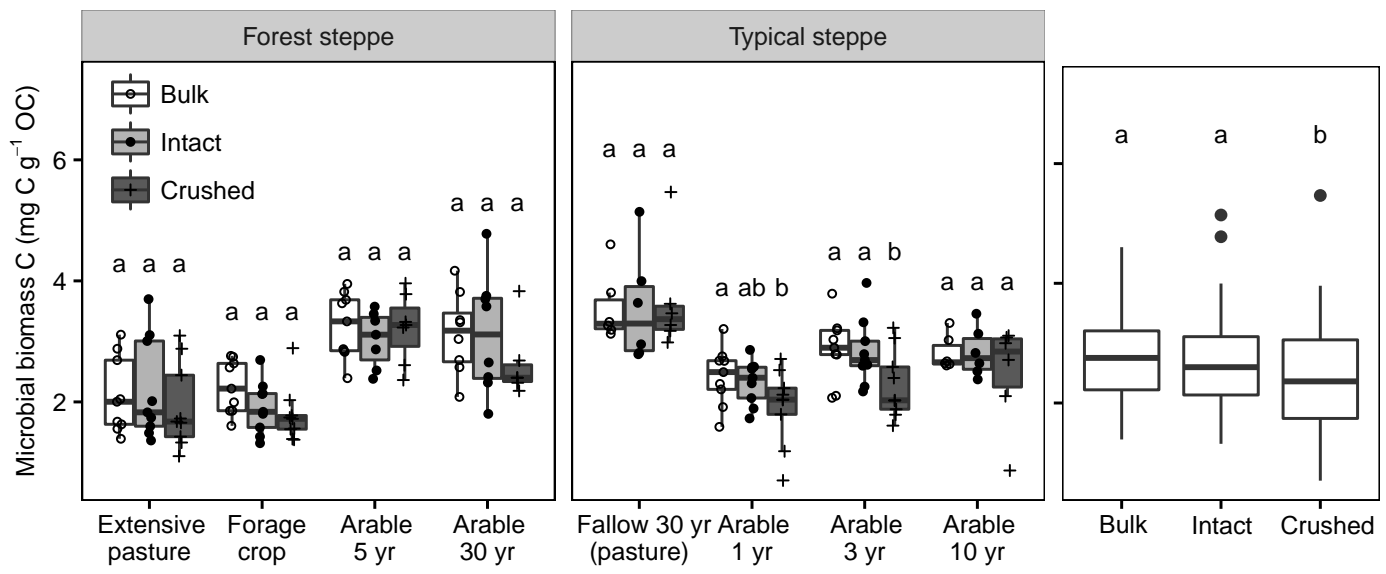

Figure 6. Microbial biomass $\mathrm{C}\left(\mathrm{mg} \mathrm{Cg}^{-1} \mathrm{OC}\right)$ for eight plots within two steppe types and the three fractions bulk soil, intact macroaggregates, and crushed macro-aggregates. Different lowercase letters indicate significant differences between fractions within plots at $p<$ 0.05. The right panel shows differences between the three fractions averaged over all plots.

\subsection{Microbial biomass carbon}

The share of microbial biomass $\mathrm{C}$ in the total $\mathrm{OC}$ was similar in both steppe types and ranged between 1.5 and $4.0 \mathrm{mg} \mathrm{Cg}^{-1} \mathrm{OC}$, as indicated by the first and third quartile of the box plots (Fig. 6). Crushing of macro-aggregates caused a small decrease of microbial biomass $C$, which was significant when considering all plots $(p<0.05)$, while bulk soil samples and intact macro-aggregates had similar amounts of microbial biomass C. There was no correlation between the amount of OC mineralized and the share of microbial biomass $\mathrm{C}$ in total OC (Fig. S3). Moreover, the quantity of OC mineralization was not related to the amount of microbial biomass $\mathrm{C}$ per gram soil (Fig. S4).

\section{Discussion}

\subsection{Limited protection of macro-aggregate-occluded organic carbon}

Previous studies showed higher OC mineralization following macro-aggregate crushing (e.g., Beare et al., 1994; Bossuyt et al., 2002; Pulleman and Marinissen, 2004), while some studies showed no such effect (Garcia-Oliva et al., 2004; Goebel et al., 2009; Plante et al., 2009). In our study, the macro-aggregate-occluded OC fraction contributed only marginally to the OC mineralization during the entire incubation (Fig. 5, Table 3). Against our hypothesis, macroaggregate-occluded OC is not protected against decomposition in the studied soils. Subsequently, the breakdown of macro-aggregates due to soil tillage and the subsequent release of soil OC is not the reason for a decrease of soil OC contents due to soil management, as observed along the chronosequence in FS (Table 1). Plante et al. (2009) suspected that the disruption treatments used in their experi- ments (crushing of 2-4 mm aggregates to $<0.5 \mathrm{~mm}$ ) was insufficient to release large amounts of physically protected OC for decomposition, and that a considerable amount of OC was stabilized in micro-aggregates. Also Balesdent et al. (2000) provided some evidence that the proportion of physically protected $\mathrm{OC}$ is larger in micro-aggregates than in macro-aggregates. In our study, the majority of crushed macro-aggregates $(62 \pm 3 \%)$ consisted of micro-aggregates with $63-250 \mu \mathrm{m}$ size (see Sect. 2.3), and as the OC mineralization of the crushed aggregate fraction was not enhanced, we suggest that most of the OC was stabilized in the microaggregates. However, micro-aggregates are less sensitive to soil tillage (Tisdall and Oades, 1982); therefore, in light of LUC-induced OC losses, the soil OC in macro-aggregates is generally considered to be more vulnerable for destabilization than OC in micro-aggregates. This could not be confirmed for the soils under study. Nevertheless, we cannot rule out that an increased macro-aggregate turnover due to agricultural management leads to a reduced formation of microaggregates within macro-aggregates and, as a result, to lower OC contents in arable as compared to pasture soils (Six et al., 2000a).

Only a few studies determined the share of the macroaggregate-protected OC fraction in the total OC mineralization or the total macro-aggregate $\mathrm{OC}$, respectively. Beare et al. (1994) showed that macro-aggregate-protected OC accounted for about $1 \%$ of total aggregate $\mathrm{OC}$ and to about $8-23 \%$ of total mineralizable OC during 20 days of incubation. They detected a smaller macro-aggregate-protected OC mineralization in more intensively managed soils. In our study, $<1 \%$ of total macro-aggregate $\mathrm{OC}$ was stored as macro-aggregate-protected $\mathrm{OC}$, while this fraction accounted for maximum $8 \pm 4 \%$ of total OC mineralization (Table 3 ). Thus, our values are in the same order of magnitude as observed by Beare et al. (1994), who suggested that an in- 
creased macro-aggregate turnover in tilled soils is one reason for the small macro-aggregate-protected OC fraction. According to Beare et al. (1994), the physically protected but relatively labile macro-aggregate-occluded OC is released for microbial decomposition due to the frequent tillageinduced macro-aggregate breakdown. As a result, macroaggregates contain only little or no labile OC. This can be a reason in arable soils, but is unlikely in pasture soils where the macro-aggregate turnover is slower due to the absence of tillage (Six et al., 2002). In the untilled soils, therefore, other factors are probably responsible for the absence of labile macro-aggregate-protected $\mathrm{OC}$.

The mineralization of $\mathrm{OC}$ is driven by microorganisms and, thus, can be affected by disturbances of their physical environment (Schimel and Schaeffer, 2012). Garcia-Oliva et al. (2004) observed lower OC mineralization in crushed than in intact macro-aggregates and attributed this finding to a reduced microbial activity in crushed samples, which they explained by a disturbed soil environment with possibly anaerobic conditions. Balesdent et al. (2000) reviewed the effect of aggregate crushing on the mineralization of soil OM and indicated a reduced microbial biomass in crushed aggregates as a possible reason for similar OC mineralization rates in intact and crushed aggregates. In our study, crushed macroaggregates contained slightly but significantly less microbial biomass $\mathrm{C}$ than intact macro-aggregates (Fig. 6). This may have contributed to the missing effect of aggregate crushing on OC mineralization.

Besides stabilization of OC by physical occlusion within aggregates, formation of mineral-organic associations can be an important mechanism for OC stabilization (von Lützow et al., 2006). Bischoff et al. (2016) showed that a large OC fraction ( $>90 \%$ of total OC) is associated with mineral surfaces in soils of the Kulunda steppe, which is much more than generally observed in steppe soils (Kalinina et al., 2011; Plante et al., 2010). In our study, about $38 \pm 3 \%$ of the crushed macro-aggregate fraction were particles $<63 \mu \mathrm{m}$, in which the proportion of particulate OC is usually very low (Christensen, 2001). Based on the similar OC mineralization rates of intact and crushed macro-aggregates, this suggests that a considerable OC proportion is stabilized by mineral surfaces. As a result, $\mathrm{OC}$ in crushed aggregates was not available to microorganisms and thus did not enhance soil OC mineralization.

Summing up, our results suggest that the tillage-induced breakdown of macro-aggregates and the subsequent release of $\mathrm{OM}$ is not the key factor driving $\mathrm{OC}$ losses due to LUC in the studied soils. In contrast, most OC in steppe soils of Siberia appears protected by occlusion within micro-aggregates and/or association with minerals. This, in part, contrasts with previous research of prairie soils from the North American Great Plains. Elliott (1986) and Cambardella and Elliott $(1993,1994)$ found that macroaggregate-occluded OC was rapidly lost after conversion of grassland to cropland due to the breakdown of macro- aggregates and concluded that this fraction is protected from decomposition. Though more recent research (e.g., Six et al., 2000a) indicated that micro-aggregates, which are formed within existing macro-aggregates, are decisive for OC stabilization in agroecosystems, it is still widely accepted that the decomposition of previously occluded macro-aggregate $\mathrm{OC}$ is another key factor controlling the decline of OC after grassland to cropland conversion. Our results imply, that this is not the case in the Siberian steppe soils. A possible explanation for the observed differences are smaller soil OC inputs by crop residues and rhizodeposits in the Siberian soils, resulting in smaller proportions of particulate OC (Castellano et al., 2015) and, thus, less possibilities for the formation of macro-aggregate-occluded OC.

\subsection{Effect of land management and soil characteristics on the mineralization potential of soil organic carbon}

As shown in previous studies the conversion from grassland to arable land caused a decrease of labile soil OC (Plante et al., 2011; Poeplau and Don, 2013), which corresponds to OC with fast turnover rates. In line with this, we found a larger fast OC pool under pasture than under arable land, while the proportion of the fast $\mathrm{OC}$ pool was unaffected by the intensity of agricultural use and the time since land use conversion (Fig. 4). This means, that the fast OC pool is highly vulnerable to LUC, as the majority of this pool was rapidly lost within 1-5 years after grassland to cropland conversion. At the same time higher intensity of agricultural land use and longer time since land use conversion tended to shorten MRTs in the fast and slow OC pool of the soils in FS (Table 2), thus reducing the potential to sequester soil OC. This is in line with Beare et al. (1994) and Grandy and Robertson (2007), who reported that the MRT of soil OC pools from laboratory incubations were shorter under high than under low land use intensity. Beare et al. (1994) argued that the frequent soil disturbance in tilled soils impedes a strong association of OC with mineral surfaces, which in turn leads to a low protection of OC against microbial decomposition and thus fast turnover rates. Moreover, McLauchlan (2006) showed that the MRT of the fast OC pool was shorter in arable soils than in soils that were left as fallow, which is supported by our results. We should consider that our observations were derived from long-term laboratory incubations and that we expect the difference of MRTs between arable and pasture soils to be even more pronounced under field conditions, as soil tillage generally accelerates the turnover of soil OC. Moreover, soil OC inputs by plant residues are probably reduced in arable soils. This, together with faster soil OC turnover times would lead to a decrease of total soil $\mathrm{OC}$ as a result of agricultural land management.

We observed differences in the amount of mineralized soil OC between the two sites. Mineralization rates were smaller in the more clayey soils of FS than in the soils of TS with 
larger sand content. Many studies showed smaller OC mineralization rates in clayey soils as compared to sandy soils, as OC is stabilized by clay-sized minerals and thus protected against decomposition by microorganisms (Franzluebbers, 1999; Franzluebbers and Arshad, 1997; Harrison-Kirk et al., 2013). Moreover, Bischoff et al. (2016) showed that the proportion of labile particulate OC tended to increase with aridity in the soils under study. This means, that soils in TS would have larger amounts of bioavailable and easily decomposable particulate OC than soils in FS, which in turn could lead to increased OC mineralization in the soils of TS. The differences between both sites with respect to their soil OC mineralization rates could therefore be attributed to a different contribution of mineral-organic associations, with less mineralbound OC in TS as compared to FS. Another explanation for the larger OC mineralization rates in TS could be the slightly smaller $\mathrm{C}: \mathrm{N}$ ratios in these soils, indicating a larger $\mathrm{N}$ availability. This is in line with the observation that increased $\mathrm{N}$ availability during laboratory incubation enhances OC mineralization rates (Bossuyt et al., 2001).

Interestingly, we found a smaller variation of the percentage of OC mineralized (i.e., OC mineralization rates) between samples from plots with long duration of arable land use (Fig. 2). This is possibly due to the fact that tillage homogenizes the soil within plow depth and consequently minimizes the heterogeneity of soil OC at the field scale. This idea is supported by Schrumpf et al. (2011), who showed that soil OC contents are less variable under cropland as compared to grassland. We, therefore, conclude that continuous agricultural management obliterates differences of soil OC properties across a field.

\section{Conclusion}

This study set out to determine the quantity of macroaggregate-protected OC in Siberian steppe soils under different land use as function of land use intensity and time since LUC from pasture to arable land. This was done by crushing of dry-sieved macro-aggregates $(250-2000 \mu \mathrm{m})$ to $<250 \mu \mathrm{m}$ and subsequent incubation of crushed and intact macroaggregates at $20^{\circ} \mathrm{C}$ and $60 \%$ WHC during 401 days along two agricultural chronosequences of the Kulunda steppe. The effect of macro-aggregate crushing on OC mineralization was negligible along the two chronosequences. Macroaggregate-protected OC accounted for $<1 \%$ of the total macro-aggregate OC content and for a maximum of $8 \pm 4 \%$ of total mineralized OC. The majority of macro-aggregateprotected $\mathrm{OC}$ was mineralized during the beginning of the incubation, showing that this represents a labile fraction with fast turnover rates. Our results imply that the tillage-induced breakdown of macro-aggregates has not reduced the OC contents in the studied soils. In contrast, our data suggest that mainly OC occluded within micro-aggregates and/or associated with mineral surfaces is decisive for OC stabilization in these soils. Long-term incubations of bulk soil samples revealed not only that LUC from pasture to arable land but also the cultivation with forage crops caused a rapid decrease of a fast soil OC pool within 1-5 years of agricultural management. At the same time the MRT tended to become shorter in the fast and slow OC pool with increasing land use intensity and time since LUC at one of the investigated sites. This suggests that the potential of the soils to sequester OC is reduced under agricultural management, as $\mathrm{OC}$, which enters the soil from above- or below-ground, is released to the atmosphere within few decades. The difference of turnover times between arable and pasture soils is probably even more pronounced under field conditions, as soil tillage leads to a frequent disturbance of the soil environment, which additionally accelerates soil OC mineralization. Thus, we conclude that the decrease of soil OC contents in the course of LUC is attributed to faster soil OC turnover under arable land as compared to pasture at a reduced plant residue input but not to the tillage-induced release of macro-aggregate-occluded soil OC.

Data availability. The data of the study can be found as a *.csv file in the Supplement.

\section{The Supplement related to this article is available online at doi:10.5194/bg-14-2627-2017-supplement.}

Competing interests. The authors declare that they have no conflict of interest.

Acknowledgements. Financial support was provided by the German Federal Ministry of Education and Research (BMBF) in the framework of the KULUNDA project (01 LL 0905). Olga Shibistova and Georg Guggenberger appreciate funding from the Russian Ministry of Education and Science (No.14.B25.31.0031). We thank the entire KULUNDA team for great collaboration and good team spirit. We are thankful to all farmers of the Kulunda steppe for collaboration during sampling and Lukas Gerhard for indispensable assistance in the field. Thanks for laboratory assistance to Silke Bokeloh, Elke Eichmann-Prusch, Roger-Michael Klatt, Pieter Wiese and Fabian Kalks, while Leopold Sauheitl is appreciated for guidance in the laboratory. Andrea Hartmann is acknowledged for helpful support on the scanning electron microscope. Thanks to Norman Gentsch for valuable scientific discussions on the manuscript, while we acknowledge Frank Schaarschmidt for statistical support. We thank two anonymous reviewers for valuable suggestions on the manuscript. The publication of this article was funded by the Open Access Fund of Leibniz Universität Hannover.

Edited by: Y. Kuzyakov

Reviewed by: two anonymous referees 


\section{References}

Balesdent, J., Chenu, C., and Balabane, M.: Relationship of soil organic matter dynamics to physical protection and tillage, Soil Till. Res., 53, 215-230, doi:10.1016/S0167-1987(99)00107-5, 2000.

Bates, D., Mächler, M., and Bolker, B.: Fitting linear mixed-effects models using lme4, J. Stat. Softw., 1-51, available at: https:// arxiv.org/pdf/1406.5823.pdf (last access: 10 May 2017), 2012.

Beare, M. H., Hendrix, P. F., Cabrera, M. L., and Coleman, D. C.: Aggregate-protected and unprotected organic matter pools in conventional- and no-tillage soils, Soil Sci. Soc. Am. J., 58, 787795, doi:10.2136/sssaj1994.03615995005800030021x, 1994.

Beniston, J. W., DuPont, S. T., Glover, J. D., Lal, R., and Dungait, J. A. J.: Soil organic carbon dynamics 75 years after land-use change in perennial grassland and annual wheat agricultural systems, Biogeochemistry, 120, 37-49, doi:10.1007/s10533-0149980-3, 2014.

Bischoff, N., Mikutta, R., Shibistova, O., Puzanov, A., Reichert, E., Silanteva, M., Grebennikova, A., Schaarschmidt, F., Heinicke, S., and Guggenberger, G.: Land-use change under different climatic conditions: Consequences for organic matter and microbial communities in Siberian steppe soils, Agr. Ecosyst. Environ., 235, 253-264, doi:10.1016/j.agee.2016.10.022, 2016.

Bossuyt, H., Denef, K., Six, J., Frey, S. D., Merckx, R., and Paustian, K.: Influence of microbial populations and residue quality on aggregate stability, Appl. Soil Ecol., 16, 195-208, doi:10.1016/S0929-1393(00)00116-5, 2001.

Bossuyt, H., Six, J., and Hendrix, P. F.: Aggregate-protected carbon in no-tillage and conventional tillage agroecosystems using carbon-14 labeled plant residue, Soil Sci. Soc. Am. J., 66, 19651973, doi:10.2136/sssaj2002.1965, 2002.

Cambardella, C. A. and Elliot, E. T.: Particulate soil organic-matter changes across a grassland cultivation sequence, Soil Sci. Soc. Am. J., 56, 777-783, doi:10.2136/sssaj1992.03615995005600030017x, 1992.

Cambardella, C. A. and Elliott, E. T.: Carbon and nitrogen distribution in aggregates from cultivated and native grassland soils, Soil Sci. Soc. Am. J., 57, 1071-1076, doi:10.2136/sssaj1993.03615995005700040032x, 1993.

Cambardella, C. A. and Elliott, E. T.: Carbon and nitrogen dynamics of soil organic matter fractions from cultivated grassland soils, Soil Sci. Soc. Am. J., 58, 123-130, doi:10.2136/sssaj1994.03615995005800010017x, 1994.

Castellano, M. J., Mueller, K. E., Olk, D. C., Sawyer, J. E., and Six, J.: Integrating plant litter quality, soil organic matter stabilization, and the carbon saturation concept, Glob. Change Biol., 21, 3200-3209, doi:10.1111/gcb.12982, 2015.

Christensen, B. T.: Physical fractionation of soil and structural and functional complexity in organic matter turnover, Eur. J. Soil Sci., 52, 345-353, doi:10.1046/j.1365-2389.2001.00417.x, 2001.

DIN ISO 11277: Soil quality - determination of particle size distribution in mineral soil material - method by sieving and sedimentation, ISO, International Organization for Standardization, 2002.

Elliott, E. T.: Aggregate structure and carbon, nitrogen, and phosphorus in native and cultivated soils, Soil Sci. Soc. Am. J., 50, 627-633, doi:10.2136/sssaj1986.03615995005000030017x, 1986.
FAO: Lecture notes on the major soils of the world, edited by: Driessen, P., Deckers, J., Spaargaren, O., and Nachtergaele, F., World soil Resour. reports, 94, 336, doi:10.1136/gut.27.11.1400b, 2001.

FAO: FAO Statistical yearbook 2013 - World food and agriculture, Rome, 2013.

Franzluebbers, A. J.: Potential $\mathrm{C}$ and $\mathrm{N}$ mineralization and microbial biomass from intact and increasingly disturbed soils of varying texture, Soil Biol. Biochem., 31, 1083-1090, doi:10.1016/S0038-0717(99)00022-X, 1999.

Franzluebbers, A. J. and Arshad, M. A.: Soil microbial biomass and mineralizable carbon of water-stable aggregates, Soil Sci. Soc. Am. J., 61, 1090-1097, doi:10.2136/sssaj1997.03615995006100040015x, 1997.

Frühauf, M.: Landnutzungs- und Ökosystementwicklung in den südsibirischen Agrarsteppen, Geogr. Rundschau, 1, 46-53, 2011.

Garcia-Oliva, F., Oliva, M., and Sveshtarova, B.: Effect of soil macroaggregates crushing on $\mathrm{C}$ mineralization in a tropical deciduous forest ecosystem, Plant Soil, 259, 297-305, doi:10.1023/B:PLSO.0000020978.38282.dc, 2004.

Goebel, M.-O., Woche, S. K., and Bachmann, J.: Do soil aggregates really protect encapsulated organic matter against microbial decomposition?, Biologia (Bratisl)., 64, 443-448, doi:10.2478/s11756-009-0065-z, 2009.

Grandy, A. S. and Robertson, G. P.: Land-use intensity effects on soil organic carbon accumulation rates and mechanisms, Ecosystems, 10, 58-73, doi:10.1007/s10021-006-9010-y, 2007.

Gupta, V. V. S. R. and Germida, J. J.: Distribution of microbial biomass and its activity in different soil aggregate size classes as affected by cultivation, Soil Biol. Biochem., 20, 777-786, doi:10.1016/0038-0717(88)90082-X, 1988.

Harrison-Kirk, T., Beare, M. H., Meenken, E. D., and Condron, L. M.: Soil organic matter and texture affect responses to dry/wet cycles: Effects on carbon dioxide and nitrous oxide emissions, Soil Biol. Biochem., 57, 43-55, doi:10.1016/j.soilbio.2012.10.008, 2013.

Hijmans, R. J., Cameron, S. E., Parra, J. L., Jones, P. G., and Jarvis, A.: Very high resolution interpolated climate surfaces for global land areas, Int. J. Climatol., 25, 1965-1978, doi:10.1002/joc.1276, 2005.

Hothorn, T., Bretz, F., and Westfall, P.: Simultaneous inference in general parametric models, Biometrical J., 50, 346-363, doi:10.1002/bimj.200810425, 2008.

Hurisso, T. T., Norton, J. B., and Norton, U.: Labile soil organic carbon and nitrogen within a gradient of dryland agricultural land-use intensity in Wyoming, USA, Geoderma, 226-227, 1-7, doi:10.1016/j.geoderma.2014.02.025, 2014.

IUSS Working Group WRB: World reference base for soil resources 2014, International soil classification system for naming soils and creating legends for soil maps, World Soil Resour. Reports No. 106, 1-191, doi:10.1017/S0014479706394902, 2014.

Kalinina, O., Krause, S.-E., Goryachkin, S. V., Karavaeva, N. A., Lyuri, D. I., and Giani, L.: Self-restoration of postagrogenic chernozems of Russia: Soil development, carbon stocks, and dynamics of carbon pools, Geoderma, 162, 196-206, doi:10.1016/j.geoderma.2011.02.005, 2011.

Kleber, M., Eusterhues, K., Keiluweit, M., Mikutta, C., Mikutta, R., and Nico, P. S.: Mineral-organic associations: formation, proper- 
ties, and relevance in soil environments, Adv. Agron., 130, 1140, doi:10.1016/bs.agron.2014.10.005, 2015.

Kuznetsova, A., Brockhott, P. B., and Christensen, R. H. B.: lmerTest: Tests in linear mixed effects models, $\mathrm{R}$ package version 2.0-25, available at: http://cran.r-project.org/package=lmerTest (10 May 2017), 2015.

Lal, R.: Soil carbon sequestration impacts on global climate change and food security, Science, 304, 1623-1627, doi:10.1126/science.1097396, 2004.

Lehmann, J. and Kleber, M.: The contentious nature of soil organic matter, Nature, 528, 60-68, doi:10.1038/nature16069, 2015.

Lenth, R. V. and Herve, M.: 1smeans: Least-squares means, R package version 2.17 , available at: http://cran.r-project.org/package= lsmeans, 2015.

Loftfield, N., Flessa, H., Augustin, J., and Beese, F.: Automated gas chromatographic system for rapid analysis of the atmospheric trace gases methane, carbon dioxide, and nitrous oxide, J. Environ. Qual., 26, 560-564, doi:10.2134/jeq1997.00472425002600020030x, 1997.

McLauchlan, K. K.: Effects of soil texture on soil carbon and nitrogen dynamics after cessation of agriculture, Geoderma, 136, 289-299, doi:10.1016/j.geoderma.2006.03.053, 2006.

Mikhailova, E. A., Bryant, R. B., Vassenev, I. I., Schwager, S. J., and Post, C. J.: Cultivation effects on soil carbon and nitrogen contents at depth in the russian Chernozem, Soil Sci. Soc. Am. J., 64, 738-745, doi:10.2136/sssaj2000.642738x, 2000.

Plante, A. F., Six, J., Paul, E. A., and Conant, R. T.: Does physical protection of soil organic matter attenuate temperature sensitivity?, Soil Sci. Soc. Am. J., 73, 1168-1172, doi:10.2136/sssaj2008.0351, 2009.

Plante, A. F., Virto, I., and Malhi, S. S.: Pedogenic, mineralogical and land-use controls on organic carbon stabilization in two contrasting soils, Can. J. Soil Sci., 90, 15-26, doi:10.4141/CJSS09052, 2010.

Plante, A. F., Fernández, J. M., Haddix, M. L., Steinweg, J. M., and Conant, R. T.: Biological, chemical and thermal indices of soil organic matter stability in four grassland soils, Soil Biol. Biochem., 43, 1051-1058, doi:10.1016/j.soilbio.2011.01.024, 2011.

Poeplau, C. and Don, A.: Sensitivity of soil organic carbon stocks and fractions to different land-use changes across Europe, Geoderma, 192, 189-201, doi:10.1016/j.geoderma.2012.08.003, 2013.

Pulleman, M. M. and Marinissen, J. C. Y.: Physical protection of mineralizable $\mathrm{C}$ in aggregates from longterm pasture and arable soil, Geoderma, 120, 273-282, doi:10.1016/j.geoderma.2003.09.009, 2004.

R Core Team: R: A language and environment for statistical computing, available at: http://www.r-project.org/, 2015.

Rodionov, A., Amelung, W., Urusevskaja, I., and Zech, W.: Beziehungen zwischen Klimafaktoren und C-, N-Pools in Partikelgrössen-Fraktionen zonaler Steppenböden Russlands, Z. Pflanz. Bodenkunde, 161, 563-569, 1998.

Sainju, U. M.: Carbon and nitrogen pools in soil aggregates separated by dry and wet sieving methods, Soil Sci., 171, 937-949, doi:10.1097/01.ss0000228062.30958.5a, 2006.
Schimel, J. P. and Schaeffer, S. M.: Microbial control over carbon cycling in soil, Front. Microbiol., 3, 1-11, doi:10.3389/fmicb.2012.00348, 2012.

Schlichting, E., Blume, H.-P., and Stahr, K.: Bodenkundliches Praktikum - Eine Einführung in pedologisches Arbeiten für Ökologen, insbesondere Land- und Forstwirte, und für Geowissenschaftler, 2nd Edn., Blackwell Wissenschafts-Verlag Berlin, Wien, Austria, 1995.

Schrumpf, M., Schulze, E. D., Kaiser, K., and Schumacher, J.: How accurately can soil organic carbon stocks and stock changes be quantified by soil inventories?, Biogeosciences, 8, 1193-1212, doi:10.5194/bg-8-1193-2011, 2011.

Six, J., Elliott, E., and Paustian, K.: Soil macroaggregate turnover and microaggregate formation: a mechanism for $\mathrm{C}$ sequestration under no-tillage agriculture, Soil Biol. Biochem., 32, 2099-2103, doi:10.1016/S0038-0717(00)00179-6, 2000a.

Six, J., Paustian, K., Elliott, E. T., and Combrink, C.: Soil structure and organic matter: I. Distribution of aggregate-size classes and aggregate-associated carbon, Soil Sci. Soc. Am. J., 64, 681-689, doi:10.2136/sssaj2000.642681x, 2000b.

Six, J., Feller, C., Denef, K., Ogle, S. M., Moraes, J. C., and Albrecht, A.: Soil organic matter, biota and aggregation in temperate and tropical soils - effects of no-tillage, Agronomie, 22, 755-775, doi:10.1051/agro:2002043, 2002.

Tian, J., Pausch, J., Yu, G., Blagodatskaya, E., Gao, Y., and Kuzyakov, Y.: Aggregate size and their disruption affect ${ }^{14} \mathrm{C}$ labeled glucose mineralization and priming effect, Appl. Soil Ecol., 90, 1-10, doi:10.1016/j.apsoil.2015.01.014, 2015.

Tisdall, J. and Oades, J.: Organic matter and water-stable aggregates in soils, J. Soil Sci., 33, 141-163, doi:10.1111/j.13652389.1982.tb01755.x, 1982.

Vance, E. D., Brookes, P. C., and Jenkinson, D. S.: An extraction method for measuring soil microbial biomass C, Soil Biol. Biochem., 19, 703-707, doi:10.1016/0038-0717(87)900526, 1987.

VandenBygaart, A. J., Gregorich, E. G., and Angers, D. A.: Influence of agricultural management on soil organic carbon: A compendium and assessment of Canadian studies, Can. J. Soil Sci., 83, 363-380, doi:10.4141/S03-009, 2003.

von Lützow, M., Kögel-Knabner, I., Ekschmitt, K., Matzner, E., Guggenberger, G., Marschner, B., and Flessa, H.: Stabilization of organic matter in temperate soils: Mechanisms and their relevance under different soil conditions - A review, Eur. J. Soil Sci., 57, 426-445, doi:10.1111/j.1365-2389.2006.00809.x, 2006.

Walthert, L., Graf, U., Kammer, A., Luster, J., Pezzotta, D., Zimmermann, S., and Hagedorn, F.: Determination of organic and inorganic carbon, $\delta 13 \mathrm{C}$, and nitrogen in soils containing carbonates after acid fumigation with $\mathrm{HCl}$, J. Plant Nutr. Soil Sc., 173, 207-216, doi:10.1002/jpln.200900158, 2010.

Wickham, H.: ggplot2: Elegant graphics for data analysis, SpringerVerlag, New York, USA, 213 pp., doi:10.1007/978-0-387-981413, 2009. 